Postgrad. MED. J., (1966), 42, 138

\title{
THE WINDSOR AND DISTRICT POSTGRADUATE MEDICAL CENTRE
}

\author{
JOHN LISTER, M.D., F.R.C.P.
}

Clinical Tutor.

\begin{abstract}
AFTER the Oxford Conference of 1961 Windsor was selected by the British Postgraduate Medical Federation and the North West Metropolitan Regional Hospital Board as one of the sites for the development of a regional postgraduate centre. Unfortunately no grant was received from the Nuffield Provincial Hospitals Trust which sponsored a number of pilot experiments in this field, nor was it possible to obtain assistance from the King's Fund since Windsor is outside the metropolitan area.

In spite of this discouraging lack of financial support it was felt by the local Postgraduate Committee that a suitably equipped building was essential if the postgraduate activities of the district were to be successfully co-ordinated. The minimum requirements appeared to be:
\end{abstract}

1. A lecture theatre to seat at least 100 .

2. A library which should be so built that it could also be used as an extension of the lecture theatre.

3. A small seminar room which would also serve as a club room.

4. Office accommodation, a small kitchen and toilet facilities.

The minimum cost to provide a building with this accommodation, assuming there would be no cost for the land, was estimated at $£ 10,000$ and it was estimated that a further $£ 5,000$ would be required to see the building adequately equipped. It was also thought that a sum of approximately $£ 1,500$ per annum would be required for running expenses, one of the major items being a secretary's salary.

These requirements were explained to a number of local industrialists in July 1963 and within three months five firms had agreed to become major sponsors of the project and each guaranteed a capital sum of $£ 2,000$ together with the promise of an annual contribution towards running costs. This generous gesture enabled plans to be drawn up and sent out to tender while a Trust Deed was prepared and eventually approved by the Ministry of Education as an educational trust and then accepted by the Charity Commissioners as a charitable body. The Managing Directors of the five sponsoring firms became the first Trustees and invited the British Post- graduate Medical Federation to nominate $a \stackrel{\Phi}{\circ}$ further Trustee to represent the university in-œ terest.

A local appeal realised $£ 6,700$ over the nextfour months and the financial position wase further strengthened by the Windsor Groupo Hospital Management Committee joining the five industrial firms in also guaranteeing $£ 2,000^{-}$. from its meagre "free monies" and by the North West Metropolitan Regional Hospital ${ }_{\circ \infty}^{+}$ Board making a grant of $£ 2,000$ towards the ${ }^{+}$ cost of equipment when Treasury regulations $\vec{\omega}$ were relaxed last year and permitted the ex-o penditure of Exchequer funds to assist such projects. This relaxation also provided the hope $\vec{T}_{T}$ that running costs would be met from Exchequer: funds and in this light the original sponsors agreed to change their initial offer of guaranteeing $£ 2,000$ each to making outright gifts $8 \mathrm{f}-{ }_{0}$ $£ 2,000$ each provided they were not called up to make annual contributions towards runnim్g. costs.

As a result of this combined effort a pleasant and functional building has been erected within

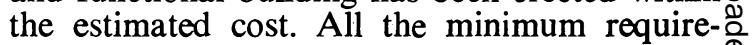
ments have been fulfilled and the spacious $\varnothing$ library is divided from the lecture room by $\overrightarrow{\overrightarrow{0}}$ sound-proof folding doors which when opened 3 can increase the capacity of the lecture room to about 200. A room has also been provided? where smaller meetings can be held and since this room has been provided with a bar it $\underline{3}$. will also fulfil the role of a club room. Adequate office and neccessary ancillary services $\frac{3}{8}$. have also been provided.

The successful completion of the building $₹$ within two years of the approach to localo industry has been partly due to a deliberate $>$ policy of not being too ambitious and concentrating on providing minimum requirements. N

Support has come from many directions. In addition to the help from the major sponsors ${ }^{\circ}$ there have been contributions in cash and kind $\underset{\omega}{\mathcal{N}}$ from many firms in the district, from three local authorities and from many individual sub-co scribers. Local members of the medical pro- $\Phi$ fession have also contributed generously. More $\stackrel{\mathscr{\rho}}{\rightarrow}$ than 120 general practitioners and consultants $\underset{T}{0}$ have made individual contributions and the $\frac{\vec{D}}{\mathbb{D}}$ 
consultant staff of King Edward VII Hospital have contributed from the fund they have accumulated from running courses for general practitioners. The Windsor and District Medical Society has also given its support and been represented on the Postgraduate Committee.

The completion and opening of the Centre is, of course, only the completion of the first phase of the project. Its future success will depend upon the use to which it is put. For the last few years the Postgraduate Committee has published regular programmes of academic activities and it is hoped that these will be extended and that the Centre will become a meeting place both for social and academic functions for the general practitioners, consultants and local authority medical officers of the area as well as providing facilities for the junior hospital medical staff. If this hope can be realised it should help to integrate the medical services in the district and at the same time raise the general standard of medical practice.

\section{DISCUSSION}

Dr. H. W. K. ACHESON (Stoke) said that their experience had been the same as Windsor's. Their appeal had been for $£ 100,000$, because less than this would not have provided for the "greater medical profession" of the area. About $£ 20,000$ has been received from Local Authorities. They had not insisted upon financial independence but had been told at all levels that no money could be provided from National Health Service sources. With the increase in demand for postgraduate medical centres there seemed to have been a change in Ministry polioy regarding finance.

DR. WATKINSON (Leeds) wanted to know whether there was any way in which Librarians could be paid as such and DR. BOULTER (Guildford) asked whether, since technical colleges provided courses for almost anyone needing them, the Ministry of Education could contribute to postgraduate medical centres.

DR. MCCALL said that the local authorities had helped his centre on the ground that it was an educational project.

\section{CONCLUDING REMARKS}

\section{J. R. ElLIS, M.B.E., M.D., F.R.C.P.}

There seems little doubt that a meeting between all those concerned with postgraduate medical education up and down the country was long overdue. Equally there seems no doubt that ASME is the most appropriate body to call together such meetings and very obviously this conference must be but the first of those called by the Association in this field of postgraduate activity. Future conferences must, I think, be confined to more precise subjects so that we can go into greater depth in them. We must also undoubtedly provide more opportunity for discussion from the floor. This first conference was deliberately rather general and in consequence some of the discussion has inevitably been superficial. Nevertheless we have been able to achieve one of our first and most important objectives, namely a greater understanding of the extent to which very many different bodies and organisations are contributing to this present rapid growth of post- graduate medical education. Many who were hitherto conscious only of their own local exertion and enterprise have become more aware of the extent to which the Ministry of Health, the University Grants Committee, the Regional Boards and the Universities are already contributing towards all that is needed.

From our wide-ranging discussions certain important points of agreement can be picked. There is agreement that Continuing Education is vital for every established doctor, for general practitioners and consultants. It is clear that Continuing Education depends for its success upon the postgraduate medical centres but also upon a good university education of undergraduates.

It is clear that a good university education depends for its success not only upon educational changes in the medical schools but most importantly upon the provision of sound Postgraduate Training for every branch of medicine, 